\title{
Candidate gene analysis supports a role for polymorphisms at TCF7L2 as risk factors for type 2 diabetes in Sudan
}

Amir T. Ibrahim', Ayman Hussain², Mohamed A. M. Salih', Omima Abdeen Ibrahim³, Sarra E Jamieson", Muntaser E. Ibrahim², Jenefer M. Blackwell ${ }^{4}$ and Hiba S. Mohamed ${ }^{2 *}$

\begin{abstract}
Background: Genetic susceptibility to type 2 diabetes (T2D) is multifactorial. A growing number of genes have been identified as risk factors for T2D across multiple ethnicities in trans-ancestry meta-analysis of large-scale genome-wide association studies. Few studies have looked at these genes in Sub-Saharan African populations. This study was undertaken to look for associations between T2D and single nucleotide polymorphisms (SNPs) in a number of the top candidate genes in a selected Sudanese population.

Methods: A total 240 T2D cases and 128 unrelated healthy control subjects were included in this study. Age, sex, weight and height were recorded, blood pressure and biochemical profiles of glucose and lipids were analysed. Single nucleotide polymorphism (SNP) genotyping was performed using the Sequenom MassARRAY ${ }^{\circledR}$ system. Fourteen SNPs were selected across 7 genes: CAPN10 (rs2975760 and rs5030952), PPARG (rs17036314 and rs1801282), IGF2BP2 (rs4402960 and rs1470579), CDKAL1 (rs9465871), HHEX (rs1111875), TCF7L2 (rs7903146, rs11196205 and rs12255372), and KCNJ11 (rs5215, rs1800467 and rs5219). Allelic and haplotype association analyses were performed under additive models in PLINK. $P \leq 0.007$ (=0.05/7 genes) was the $P$-value required to achieve correction for multiple testing.

Results: A significant genetic association between the SNPs rs7903146 (odds ratio 1.69, $95 \%$ confidence interval $1.21-2.38, P=0.002$ ) and rs12255372 (odds ratio 1.70, $95 \%$ confidence interval 1.20-2.41, $P=0.003$ ) at TCF7L2 and T2D was found in Sudanese population. These associations were retained after adjusting for age, sex and BMI (e.g. rs7903146: odds ratio 1.70, $P_{\text {adj:age/sex/BMI }}=0.005$ ). The strongest haplotype association (odds ratio $2.24 ; P_{\text {adj:age/sex/BMI }}=0.0003$ ) comprised the two point haplotype T_C across rs7903146 and rs11196205. Stepwise logistic regression demonstrated that SNP rs7903146 added significant main effects to rs11196205 or rs12255372, whereas the reverse was not true, indicating that the main effect for association with T2D in this population is most strongly tagged by SNP rs7903146. Adjusted analyses also provided support for protection from T2D associated with minor alleles at SNPs rs2975760 at CAPN10 (odds ratio 0.44, $95 \%$ confidence interval 0.20-0.97, $P_{\text {adj:age/sex/BMI }}=0.042$ ) and rs 1111876 at HHEX (odds ratio 0.60, $95 \%$ confidence interval 0.39- 0.93, $P_{\text {adj:age/sex/BMl }}=0.022$ ).
\end{abstract}

Conclusions: Multiethnic associations between T2D and SNPs at TCF7L2, CAPN10 and HHEX extend to Sub-Saharan Africa, specifically Sudan.

Keywords: Type 2 diabetes mellitus, Genetic polymorphism, Genetic association study, Sudan

\footnotetext{
*Correspondence: hibasalah@iend.org

${ }^{2}$ Institute of Endemic Disease, University of Khartoum, P. O. Box 102

Khartoum, Sudan

Full list of author information is available at the end of the article
} 


\section{Background}

Type 2 diabetes (T2D) is emerging as an important international health problem. The International Diabetes Federation (IDF) report that 382 million people worldwide are living with diabetes, with a further 316 million with impaired glucose tolerance and therefore at high risk from the disease [1]. Evidence published in the IDF Diabetes Atlas [1] disproves the misconception that diabetes is a disease of the wealthy. Indeed, more than $80 \%$ of people with diabetes live in low and middle-income countries, with emerging hotspots including countries in the Middle East and Sub-Saharan Africa [1]. In Sudan, Awad et al. [2] reported a prevalence of $3.4 \%$ and considered diabetes as the commonest cause of hospital admission and morbidity due to a non- communicable disease. The highest prevalence is reported in northern Sudan [3] and the lowest in the western desert regions [4], with data reported in the IDF Diabetes Atlas [1] suggesting prevalence varying from $6-10 \%$ and $60 \%$ of deaths due to diabetes occurring in people under 60 years of age.

Since the introduction of genome-wide association studies (GWAS) a large number of genes have been shown to be associated with T2D at genome-wide significance (generally accepted to be $P \leq 5 \times 10^{-8}$ [5]), including many that have been shown to have effects across multiple ethnicities [6-19] and in trans-ancestry meta-analysis of large-scale GWAS [20]. Only a few studies have looked at these genes in Arab [16, 18, 19, 21-23] or Sub-Saharan African populations $[8,17]$. In this study we looked for association between 14 single nucleotide polymorphisms (SNPs) in 7 of the top GWAS genes (TCF7L2, CDKAL1, HHEX, IGF2BP2, KCNJ11, PPARG and CAPN10) and risk of T2D in Sudan.

\section{Methods}

\section{Study area and population}

The study was approved by the ethics committee of Institute of Endemic Diseases, University of Khartoum. Written informed consent was obtained from all cases and controls, all of whom were from the population of Tuti Island, Khartoum, Sudan descended from one large family from the Mahas tribe of northern Sudan. Ascertainment of cases was by identification of patients attending Tuti Health Centres for monthly follow up. Individuals were classified as having T2D when they met all of the following criteria: (1) diagnosed with T2D by a qualified physician; (2) on a prescribed drug treatment regimen for T2D; and (3) returned biochemical test results of a fasting plasma glucose level of at least $126 \mathrm{mg} / \mathrm{dl}$ (=7 $\mathrm{mmol} / \mathrm{l}$ in SI units) based on the criteria laid by the World Health Organisation [24]. Healthy controls were selected from the general population of Tuti Island. All participants were consented for blood by venipuncture for DNA and biochemical tests (cf. below), and for recording of height and weight to determine body mass index (BMI). All participants answered a questionnaire approved by the ethics committee, and designed to collect socioeconomic data, as well as, age, sex, family history of diabetes and diagnosis.

\section{Lipid profile and glucose measurement}

Blood samples were obtained in Fluoride Oxalate and EDTA tubes from all participants after an overnight (8-12-h) fast. Plasma was used for the determination of glucose, total cholesterol, high density lipoprotein (HDL), low density lipoprotein (LDL) and triglyceride (TG). All of these parameters were measured using spectrophotometry (Spectrum lab 22PC).

\section{DNA extraction and SNPs genotyping}

The guanidine chloride-chloroform method was used for DNA extraction. SNP genotyping was carried out at Shanghai Benegene Biotechnology Co., Ltd (Shanghai, China) using the Sequenom MassARRAY ${ }^{\circledR}$ system. A total of 14 SNPs was selected for genotyping across 7 genes: CAPN10 (rs2975760 and rs5030952), PPARG (rs17036314 and rs1801282), IGF2BP2 (rs4402960 and rs1470579), CDKAL1 (rs9465871), HHEX (rs1111875), TCF7L2 (rs7903146, rs11196205 and rs12255372,), and KCNJ11 (rs5215, rs1800467 and rs5219). SNP selection was based on top SNPs reported from a number of published candidate gene, GWAS or replication studies $[8,9,12,20,25-29]$.

\section{Statistical analysis}

Statistical comparisons of demographic (age, sex) and quantitative clinical variables (systolic blood pressure, diastolic blood pressure, BMI, fasting glucose, total cholesterol, HDL, LDL, and TG) between cases and controls were analysed in Prism5 using T- tests with Welch's correction for unequal variances when applicable. All SNPs were tested for Hardy-Weinberg equilibrium. Linkage disequilibrium (r2 and D') between SNPs was determined using Haploview 4.1. Analyses to determine associations between SNPs and T2D were performed under additive, dominant and recessive models using logistic regression within PLINK [30] (http://pngu.mgh.harvard.edu/purcell/ plink), with/without adjustment for age, sex and BMI as indicated. Only data for the additive model are provided here as in every case this model was adequate to explain the associations observed. Haplotype analyses were also performed within PLINK.

\section{Results}

Demographic and clinical profile of cases and controls Demographic, clinical and biochemical parameters for 225 T2D cases (age range 20 to 89 years) and 129 healthy controls (age range 20 to 85 years) originally 
recruited into the study are presented in Table 1 . As expected, significant differences in clinical traits associated with T2D (systolic blood pressure, fasting glucose, and total cholesterol) were observed between cases and controls. Age and BMI also differed between cases and controls. Since age, sex and BMI are known to be independent risk factors for T2D [1], we adjusted for these in our genetic analyses looking for associations between SNPs and T2D. A total of 186 cases and 106 controls with complete records for age, sex, and BMI were taken forward in these adjusted association analyses as presented below.

\section{Characteristic of SNPs in the study population}

All SNPs were in Hardy-Weinberg equilibrium in the control sample $(p>0.05)$. Minor allele frequencies (MAF) for SNPs are provided in Table 2, and compared with MAF for Hapmap populations. Two SNPs, PPARG rs1801282 and KCNJ11 rs1800467, were at MAF $<0.05$ in our population and were removed from the association analyses. These low MAFs were consistent with low MAFs for these SNPs in all three HapMap populations. The remaining 12 SNPs were taken forward in the association analyses. The strict $P$-value needed to achieve statistical significance taking multiple testing into account is $P=0.004(=0.05 / 12)$. However, this is conservative since multiple SNPs within genes showed some degree of linkage disequilibrium, as might be expected given that they were selected as top SNPs for association with T2D in other populations. Therefore, $P \leq 0.007$ ( $=0.05 / 7$ genes) was used as the $P$-value required to achieve correction for multiple testing.

\section{Allelic association between candidate gene SNPs and T2D in Sudan}

DNA was available for genotyping from 190 cases and 129 controls. Table 3 provides results of logistic regression

Table 1 Clinical and biochemical parameters of type 2 diabetes cases and controls

\begin{tabular}{lccc}
\hline Trait & Controls & Cases & T test $^{\mathrm{a}}$ \\
& Mean \pm SD (n) & Mean \pm SD (n) & $P$-value \\
\hline Age (years) & $48 \pm 15(118)$ & $58 \pm 13(225)$ & $<0.001^{*}$ \\
Systolic BP (mmHg) & $122 \pm 18(104)$ & $132 \pm 22(202)$ & $<0.001^{*}$ \\
Diastolic BP (mmHg) & $75 \pm 13(105)$ & $77 \pm 15(204)$ & 0.231 \\
BMl (kg/m $\left.{ }^{2}\right)$ & $27 \pm 6(107)$ & $29 \pm 7(234)$ & 0.017 \\
Fasting glucose (mg/dl) & $105 \pm 32(66)$ & $155 \pm 58(124)$ & $<0.001^{*}$ \\
Cholesterol (mg/dl) & $198 \pm 72(67)$ & $171 \pm 63(125)$ & 0.012 \\
HDL (mg/dl) & $76 \pm 43(59)$ & $69 \pm 43(115)$ & 0.287 \\
LDL (mg/dl) & $115 \pm 58(47)$ & $104 \pm 60(95)$ & 0.281 \\
TG (mg/dl) & $129 \pm 75(66)$ & $105 \pm 68(125)$ & 0.026
\end{tabular}

${ }^{\mathrm{a}}$ T-Test with Welch's correction for unequal variance where applicable; *indicates unequal variances. $S D=$ Standard Deviation, $n=$ number of the samples, $\mathrm{BP}=$ Blood pressure, $\mathrm{BMI}=$ Body Mass Index, $\mathrm{HDL}=$ High Density Lipoprotein, LDL = Low Density Lipoproptein, TG = Triglyceride analyses to test for allelic associations between SNPs at candidate genes and T2D. In the unadjusted analysis that included all study participants with DNA available (Table 3: Column entitled Unadjusted All) two SNPs at TCF7L2, rs7903146 (odds ratio 1.69, $95 \%$ confidence intervals $1.21-2.38, P=0.002$ ) and rs12255372 (odds ratio $1.70,95 \%$ confidence intervals $1.20-2.41, P=0.003$ ), achieved $P$-values that withstand correction for multiple testing $(P<0.007)$. In the reduced data set that comprised individuals with complete data for age, sex, and BMI, the three SNPs at TCF7L2 achieved nominal $P<0.05$ (Table 3: Column entitled Unadjusted). Of the three SNPs, significance at TCF7L2 rs7903146 achieved $P<0.007$ following adjustment for age, or age and sex. This was retained after additionally adjusting for BMI, suggesting that this is a gene for T2D and not the result of confounding due to the strong correlation between BMI and T2D [1]. SNPs rs2975760 at CAPN10 and rs1111875 at HHEX also achieved nominal $P<0.05$ after adjustments for age with/ without additional adjustments for sex, or sex and BMI.

\section{Haplotype associations and stepwise logistic regression analysis for SNPs at TCF7L2}

Since all three SNPs at TCF7L2 were associated with T2D in our population, the question arises as to whether all SNPs were tagging a single functional variant, or whether multiple main effects occur. SNPs within TCF7L2 were in strong linkage disequilibrium as determined by $D^{\prime}$ (rs7903146 and rs11196205: $\mathrm{D}^{\prime}=0.94$; rs7903146 to rs12255372: $\mathrm{D}^{\prime}=0.68 ; \quad \mathrm{rs} 11196205$ to rs12255372: $D^{\prime}=0.80$ ), suggesting that all 3 SNPs may be tagging a single haplotype carrying the risk variant. This was not so strongly supported by linkage disequilibrium as determined by $\mathrm{r}^{2}$ (rs7903146 and rs11196205: $r^{2}=0.36$; rs7903146 to rs12255372: $r^{2}=0.35$; rs11196205 to rs12255372: $r^{2}=0.23$ ) which takes allele frequencies into account. It was of interest too that the minor allele at rs11196205 was associated with protection, whereas for the other two TCF7L2 SNPs the minor alleles were the risk alleles. We therefore carried out haplotype association analyses to see where the strongest associated haplotypes occur. As before (Table 3), the strongest single point association was at rs7903146 (odds ratio 1.70; $P_{\text {adj:age/sex } / \mathrm{BMI}}=0.005$ ). Notably, the associated (odds ratio $>1$ ) two point and three point risk haplotypes were on the background of the common $\mathrm{C}$ allele at rs11196205 (Table 4), with the strongest association (odds ratio 2.24; $P_{\text {adj:age/sex/BMI }}=0.0003$ ) comprising the two point haplotype T_C across rs7903146 and rs11196205. In a stepwise logistic regression analysis (Table 5), SNP rs7903146 added significant main effects to rs11196205, whereas the reverse was not true. Similarly, whilst rs7903146 added significant main effects to rs12255372, the reverse was not true. Together these 
Table 2 Details of SNPs used in this study

\begin{tabular}{|c|c|c|c|c|c|c|c|c|}
\hline \multirow[t]{2}{*}{ Gene } & \multirow[t]{2}{*}{ Chr } & \multirow[t]{2}{*}{ SNP } & \multirow[t]{2}{*}{ bp Location GRCh38 } & \multirow[t]{2}{*}{ Minor Allele } & \multirow{2}{*}{$\begin{array}{l}\text { MAF SDN }^{a} \\
N=129\end{array}$} & \multicolumn{3}{|c|}{ MAF HapMap Populations } \\
\hline & & & & & & CEU & $\mathrm{HCB}$ & YRI \\
\hline \multirow[t]{2}{*}{ CAPN10 } & 2 & rs2975760 & 240591746 & C & 0.07 & 0.16 & 0.11 & 0.01 \\
\hline & & rs5030952 & 240603286 & $\mathrm{~T}$ & 0.35 & 0.05 & 0.26 & 0.63 \\
\hline \multirow[t]{2}{*}{ PPARG } & 3 & rs17036314 & 12335246 & C & 0.26 & 0.20 & 0.22 & 0.18 \\
\hline & & rs1801282 & 12351626 & G & 0.02 & 0.08 & 0.02 & 0 \\
\hline \multirow[t]{2}{*}{ IGF2BP2 } & 3 & rs4402960 & 185793899 & G & 0.46 & 0.72 & 0.78 & 0.46 \\
\hline & & rs1470579 & 185811292 & A & 0.28 & 0.72 & 0.74 & 0.13 \\
\hline CDKAL1 & 6 & rs9465871 & 20717024 & C & 0.34 & 0.16 & 0.48 & 0.61 \\
\hline HHEX & 10 & rs1111875 & 92703125 & A & 0.25 & 0.42 & 0.69 & 0.13 \\
\hline \multirow[t]{3}{*}{ TCF7L2 } & 10 & rs7903146 & 112998590 & $\mathrm{~T}$ & 0.30 & 0.28 & 0.02 & 0.26 \\
\hline & & rs11196205 & 113047288 & G & 0.48 & 0.58 & 0.96 & 0.14 \\
\hline & & rs12255372 & 113049143 & $\mathrm{~T}$ & 0.24 & 0.22 & 0 & 0.27 \\
\hline \multirow[t]{3}{*}{ KCNJ11 } & 11 & rs5215 & 17387083 & C & 0.13 & 0.39 & 0.35 & 0.01 \\
\hline & & rs1800467 & 17387284 & G & 0.03 & 0.05 & 0 & 0.01 \\
\hline & & rs5219 & 17388025 & $\mathrm{~T}$ & 0.08 & 0.39 & 0.39 & 0 \\
\hline
\end{tabular}

${ }^{\mathrm{a}} \mathrm{MAF}$ - minor allele frequency for Sudan (SDN) healthy controls

Details include minor allele frequencies $(\mathrm{MAF})$ in control subjects $(N=129)$ from the Sudanese (SDN) study compared with CEU, HCB and YRI HapMap populations. $\mathrm{Chr}=$ chromosome; bp Location = chromosomal base pair location of the SNP in Genome Reference Consortium Human Build 38 (GRCh38)

results are consistent with a single main effect for association with T2D in this population that is most strongly tagged by SNP rs7903146.

\section{Discussion}

In the present study, we investigated a possible association between T2D in Sudan and SNPs from 6 genes (PPARG, IGF2BP2, CDKAL1, HHEX, TCF7L2, and $K C N J 11)$ that had achieved genome-wide significance in multiple GWAS undertaken across different ethnicities [31], in addition to CAPN10 which had been shown to be associated with T2D in a large study of Caucasians [26] and in Tunisia [27]. Of these, we found significant evidence for association between T2D and SNPs at TCF7L2 in our Sudanese population, and suggestive evidence for associations at SNPs in CAPN10 and HHEX. Given the limitations of our sample size, we cannot discount the possibility that further associations with SNPs in more of these genes would be found in this population if larger sample sizes were employed. However, relatively few studies have determined the role of common global T2D associated genetic variants in Sub-Saharan Africa, and to our knowledge this is the first study to provide evidence for associations between T2D and these important diabetes genes in a Sudanese population. Thus our study contributes to the growing need to replicate associations observed in GWAS carried out predominantly in Caucasian populations.

CAPN10 is of some interest as the first T2D gene to have been identified in a genome wide linkage scan [32], followed by positional cloning [33]. Subsequent large- scale meta-analysis of 13,628 subjects found only a modest effect size (odds ratio 1.15; $95 \%$ confidence intervals 1.07 1.23; $P=0.0002$ ) for allele T at SNP rs2975760 as a risk factor for T2D [26], and no GWAS have reported $P<1 \times 10^{-5}$ for association between T2D and CAPN10 as currently recorded in the NCBI Catalog of published GWAS [31]. Some evidence for associations with larger effect sizes (odds ratios 1.35 to 1.61 ) were recently reported for SNPs at CAPN10 and risk of T2D in a Tunisian Arab population [27]. Here we show that the T allele at SNP rs2975760 was also associated with a larger effect size (odds ratio 2.38; $95 \%$ confidence interval 1.09-5.26; $P=0.03$ ) in the Sudanese study population following adjustment for age. Further work is required to determine whether this is indicative of population-specific roles for polymorphisms at CAPN10 as risk factors for T2D in African populations.

The association at HHEX is also of interest given prior strong candidacy of this gene as a risk factor for T2D in multiple other populations $[8,9,20]$, in this case well supported by results of multiple GWAS including transancestry studies recorded in the NCBI Catalog of published GWAS [31]. HHEX belongs to a large family of transcription factors that are distinguished by a 60 amino acid conserved DNA-binding homeodomain. It is expressed in the anterior visceral endoderm during early development and in some adult tissues of endodermal origin, including liver and thyroid. In humans HHEX is associated with decreased insulin secretion in response to oral glucose stimulation, while knockout mouse studies demonstrate that the gene is a regulator of glucosestimulated insulin secretion [34]. HHEX is located in a 
Table 3 Association between SNPs and T2D in the Sudan study population

\begin{tabular}{|c|c|c|c|c|c|c|c|c|c|c|c|c|c|c|c|c|c|c|c|c|c|c|c|c|c|c|}
\hline \multirow[t]{2}{*}{ Chr } & \multirow[t]{2}{*}{ Gene } & \multirow[t]{2}{*}{ SNP } & \multirow{2}{*}{$\begin{array}{l}\text { bp } \\
\text { Location }\end{array}$} & \multirow[t]{2}{*}{ A1 } & \multirow[t]{2}{*}{$N$} & \multicolumn{4}{|c|}{ Unadjusted All } & \multirow[t]{2}{*}{$\mathrm{N}$} & \multicolumn{4}{|c|}{ Unadjusted } & \multicolumn{4}{|c|}{ Adj Age } & \multicolumn{4}{|c|}{ Adj Age, Sex } & \multicolumn{4}{|c|}{ Adj Age, Sex, BMl } \\
\hline & & & & & & OR & L95 & U95 & $\mathrm{P}$ & & OR & L95 & U95 & $P$ & OR & L95 & U95 & $P$ & OR & L95 & U95 & $\mathrm{P}$ & OR & L95 & U95 & $P$ \\
\hline & & & & C & 317 & 0.62 & 0.31 & 1.24 & 0.175 & 259 & 0.52 & 0.25 & 1.07 & 74 & 42 & 0.19 & 0.92 & 0 & 0.44 & 0.20 & 0.96 & 10 & 0.44 & 0.20 & 0.97 & .042 \\
\hline & APN10 & 5030952 & & T & 314 & 80 & 0.57 & 1.12 & 0.197 & & 0.78 & 0.54 & 1.15 & 208 & 0.82 & 0.55 & 1.21 & 0.314 & 0.80 & 0.54 & 1.20 & 0.280 & 0.80 & 0.54 & 1.19 & 0.274 \\
\hline & ( & 17050514 & 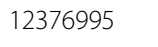 & C & 0 & 96 & 0.67 & 1.38 & 0.824 & 2 & 1.12 & 0.74 & 1.71 & 年 & 1.18 & 0.75 & 1. & 0.474 & 1.14 & 0.73 & 0 & 0.558 & 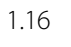 & 0.74 & .81 & 7 \\
\hline & IGF2BP2 & rs4402960 & 185511937 & G & 317 & 0.86 & 0.63 & 1.18 & 0.349 & 260 & 0.93 & 0.66 & 1.31 & 0.684 & 0.93 & 0.65 & 1.33 & 0.693 & 0.95 & 0.66 & 1.35 & 0.767 & 0.95 & 0.66 & 1.36 & 0.777 \\
\hline & $=2 B$ & rs1470579 & 185529330 & A & 316 & 1.01 & 07 & 1.42 & 0 & 8 & 1.02 & 0.70 & 1. & 0.924 & 0.99 & 0.6 & 1.46 & 0.941 & 00 & 0.6 & 1.49 & 0.986 & 2 & 0.68 & 1.51 & 0 \\
\hline & CDKAL1 & rs9465871 & & C & 5 & 1.27 & 0.94 & 1.73 & 0.120 & 7 & 1.17 & 0.83 & 1.65 & 0.376 & 1.15 & 0. & 1.65 & 0.432 & 1.15 & 0. & 1.65 & 0.456 & 1.15 & 0.80 & 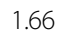 & 3 \\
\hline U & HHEX & rs1111875 & 94463132 & A & 319 & 0.71 & 0.50 & 1.01 & 0.060 & 261 & 0.68 & 0.45 & 1.02 & 0.060 & 0.61 & 0.40 & 0.94 & 0.026 & 0.61 & 0.40 & 0.95 & 0.027 & 0.60 & 0.39 & 0.93 & .022 \\
\hline 10 & TCF7L2 & 7903146 & 14758599 & $\mathrm{~T}$ & 301 & 1.69 & 1.21 & 2.38 & 0.002 & 245 & 1.62 & 1.11 & 2.37 & 0.013 & 1.75 & 1.18 & 2.61 & 0.006 & 1.81 & 1.21 & 2.70 & 0.004 & 1.79 & 1.20 & 2.67 & 0.005 \\
\hline 10 & 12 & 5 & 114807297 & G & 06 & 0.78 & 0.58 & 1.06 & 0.117 & 3 & 0 & 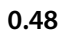 & 0.96 & 9 & 3 & 0.44 & 0 & 0.013 & .64 & 0.44 & 0.92 & 7 & 0.64 & 0.44 & 0.93 & 0.018 \\
\hline 10 & CIVL & 2 & 32 & $\mathrm{~T}$ & 319 & 70 & 1.20 & 41 & 003 & 1 & 1. & 1.04 & 2.25 & 031 & 7 & 1.06 & 2.0. & 26 & .58 & 1.07 & 2.35 & 23 & 1.60 & 1.08 & 2.38 & 0.021 \\
\hline 1 & KCNJ11 & rs5215 & 17408880 & C & 315 & 13 & 0.69 & 1.85 & 0.622 & 257 & 0.96 & 0.56 & 1.63 & 0.877 & 1.02 & 0.59 & 1.77 & 0.944 & 1.05 & 0.60 & 1.84 & 0.852 & 1.04 & 0.60 & 1.82 & 0.881 \\
\hline 1 & CNJ11 & 5219 & 409822 & T & 316 & 24 & 71 & 2.16 & 0.452 & 8 & 1.11 & 60 & 2.06 & 735 & 25 & 0.66 & 2.37 & 0.500 & 1.31 & 0.68 & 2.51 & 0.419 & 1.27 & 0.66 & 2.45 & 0.468 \\
\hline
\end{tabular}

Data are presented for an unadjusted analysis for all participants in the study, and for unadjusted and adjusted (as indicated) analyses performed in the subset of individuals for whom complete data on age, sex and BMI was available. Chr=chromosome; bp Location indicates the chromosomal base pair location of the SNP in Genome Reference Consortium Human Build 38 (GRCh38); OR= odds ratio; L95 and U95 indicate lower and upper $95 \%$ confidence intervals. Bold indicates data for SNPs with $\mathrm{P}<0.05$ 
Table 4 The effects of multiple SNPs at TCF7L2 on T2D risk in the Sudanese population

\begin{tabular}{|c|c|c|c|c|}
\hline Allele/Haplotype & Frequency & rs7903146 & rs11196205 & rs12255372 \\
\hline $\mathrm{T}$ & 0.398 & $\begin{array}{l}\mathrm{OR}=1.79 \\
P=0.005\end{array}$ & & \\
\hline C & 0.567 & & $\begin{array}{l}\mathrm{OR}=1.56 \\
P=0.018\end{array}$ & \\
\hline $\mathrm{T}$ & 0.33 & & & $\begin{array}{l}\mathrm{OR}=1.60 \\
P=0.021\end{array}$ \\
\hline TC & 0.377 & \multicolumn{3}{|c|}{$\mathrm{OR}=2.24 ; P=0.0003$} \\
\hline $\mathrm{CT}$ & 0.294 & & \multicolumn{2}{|c|}{$\mathrm{OR}=1.86 ; P=0.005$} \\
\hline TCT & 0.236 & $\mathrm{OR}=1.86 ; P$ & $=0.010$ & \\
\hline
\end{tabular}

Analysis undertaken under an additive logistic regression model (adjusted for age, sex, and BMI) to look for associations between haplotypes for the 3 SNPs at TCF7L2 and risk of T2D in the Sudanese population. Bold indicates the most significant haplotype association

region of chromosome 10 that harbors several genes involved in beta-cell function or development, including the TCF7L2 gene. However, the two genes are located some $10 \mathrm{Mb}$ apart, and their effects were independent in our study.

Associations observed between polymorphisms at TCF7L2 and T2D were the most strongly supported in our Sudanese study population. This is in keeping with GWAS and replication studies providing evidence for a role for this gene as a risk factor for T2D across multiple ethnicities [10-12, 14, 20,31,35], including a growing number of studies in African Americans [15], Sub-Saharan African $[8,17,36]$ and Arab [16, 19, 21, 23, 25, 37-39] populations. Indeed, TCF7L2 was once described as the biggest story in diabetes since HLA [40]. Exceptions include studies in Pima Indians [41] and an Australian Aboriginal population [42]. This may relate to sample size, and/or to the observation across several studies that TCF $7 L 2$ variants are associated with reduced BMI in diabetes cases (but not in controls) [40]. Hence, in a population where T2D is predominantly associated with high BMI, the association with TCF7L2 might not be so

Table 5 The effects of multiple SNPs at TCF7L2 on T2D risk in the Sudanese population

\begin{tabular}{llll}
\hline Null model & Alternative model & OR & P-value \\
\hline rs7903146 & rs7903146 + rs11196205 & 0.98 & 0.938 \\
rs7903146 & rs7903146 + rs12255372 & 1.22 & 0.437 \\
rs11196205 & rs11196205+rs7903146 & $\mathbf{2 . 0 4}$ & $\mathbf{0 . 0 1 0}$ \\
rs11196205 & rs11196205+rs12255372 & 1.53 & 0.078 \\
rs12255372 & rs12255372+rs7903146 & 1.61 & 0.052 \\
rs12255372 & rs12255372+rs11196205 & 0.77 & 0.219 \\
\hline
\end{tabular}

Stepwise logistic regression analysis to determine whether SNPs at TCF7L2 contribute separate main effects. A significant test comparing null and alternative models indicates that the marker added under the alternative model is contributing a separate main effect from the marker considered under the null hypothesis. Bold indicates nominal $P<0.05$ readily observed. In Emiratis, for example, association between TCF7L2 and T2D was only observed in a nonobese case group and not in obese diabetics [38]. In our Sudanese study, our sample size was too small to stratify by BMI, but our association between TCF7L2 variants and T2D was robust to adjustment for BMI.

TCF7L2 encodes a high-mobility group box-containing transcription factor. Collective evidence (reviewed [43]) supports the hypothesis that $\mathrm{WNT} / \beta$-catenin signaling via TCF7L2 regulates Glucagon-like peptide 1 effects in pancreatic $\beta$-cells by transcriptionally regulating its receptor. In humans, the risk $\mathrm{T}$ allele at rs7903146 (the SNP most strongly associated with T2D in our Sudanese population) strongly predicted future T2D in two independent cohorts, and was associated with impaired insulin secretion, incretin effects, and an enhanced rate of hepatic glucose production [44]. TCF7L2 expression in human islets was increased 5-fold in T2D, particularly in carriers of the TT genotype. Overexpression of TCF7L2 in human islets reduced glucose-stimulated insulin secretion. These authors conclude that the increased risk of T2D conferred by variants in TCF7L2 involves the enteroinsular axis, enhanced expression of the gene in islets, and impaired insulin secretion [44].

\section{Conclusions}

In this study we found significant evidence for association between T2D and SNPs at TCF7L2 in our Sudanese population, and suggestive evidence for associations at SNPs in CAPN10 and HHEX. The latter require confirmation in studies of larger sample sizes in Sudan, and we cannot exclude the possibility of associations with other genes examined here. Given its strong global associations with T2D, the demonstration of association between TCF7L2 and T2D in this Sudanese population is important. The cumulative evidence for associations between TCF7L2 polymorphisms across multiple ethnicities, together with growing knowledge of WNT/TCF7L2 signaling in $\beta$-cells, make it an attractive target for development of novel therapies for diabetes [43]. Our research demonstrates that T2D patients in Sudan would likely benefit from this translation of genetic research to the clinic.

\section{Ethics approval and consent to participate}

The study was approved by the ethics committee of Institute of Endemic Diseases, University of Khartoum. Written informed consent was obtained from all cases and controls.

\section{Availability of data}

Summary data are available from the corresponding author as appropriate for meta-analyses. 


\section{Abbreviations}

T2D: Type 2 diabetes; SNP: Single nucleotide polymorphisms; BMI: Body mass index; IDF: International Diabetes Foundation; GWAS: Genome-wide association study; DNA: Deoxyribonucleic acid; HLD: High density lipoprotein; LDL: Low density lipoprotein; TG: Triglyceride; MAF: Minor allele frequency.

\section{Competing interests}

The authors declare that they have no conflicting interests.

\section{Authors' contributions}

HSM, MEI and ATI contributed to design and coordination of the study. OAI was the clinician who carried out the clinical assessment: ATI collected samples and carried out experimental work. MAMS assisted with training of ATI in the laboratory. AAH assisted in statistical analysis. SEJ carried out the genetic statistical analyses. ATI, HSM and JMB contributed to the interpretation of the results and manuscript writing. All authors read and approved the final manuscript.

\section{Acknowledgements}

We thank the T2D patients and healthy volunteers from Tuti Island for their participation in this study. We would like to thank the staff at Tuti Health centers for their help. The work was undertaken as a component of postgraduate studies within our department. No external funding was used.

\section{Author details}

${ }^{1}$ Central Laboratory, Ministry of Science and Technology, Khartoum, Sudan. ${ }^{2}$ Institute of Endemic Disease, University of Khartoum, P. O. Box 102 Khartoum, Sudan. ${ }^{3}$ Tuti Health Centre, Khartoum, Sudan. ${ }^{4}$ Telethon Kids Institute, University of Western Australia, Subiaco, Australia.

\section{Received: 24 September 2015 Accepted: 25 February 2016} Published online: 01 March 2016

\section{References}

1. IDF Diabetes Atlas [http://www.idf.org/diabetesatlas]. Accessed January 2015.

2. Awad MA, Ahmed N. Diabetes mellitus in Sudan: The size of the problem and the possibilities for efficient care. Pract Diabetes Int. 2001;18(9):324-7.

3. Elbagir MN, Eltom MA, Elmahadi EM, Kadam IM, Berne C. A populationbased study of the prevalence of diabetes and impaired glucose tolerance in adults in northern Sudan. Diabetes Care. 1996;19(10):1126-8.

4. Mohammed KS. Postprandial glucose as marker of glycemic control in Type II Sudanese diabetics. Sudanese J Public Health. 2006;1(4):277-88.

5. Panagiotou OA, loannidis JP. What should the genome-wide significance threshold be? Empirical replication of borderline genetic associations. Int J Epidemiol. 2012;41(1):273-86.

6. Iwata M, Maeda S, Kamura Y, Takano A, Kato H, Murakami S, Higuchi K, Takahashi A, Fujita H, Hara K, et al. Genetic risk score constructed using 14 susceptibility alleles for type 2 diabetes is associated with the early onset of diabetes and may predict the future requirement of insulin injections among Japanese individuals. Diabetes Care. 2012:35(8):1763-70.

7. Williams AL, Jacobs SB, Moreno-Macias H, Huerta-Chagoya A, Churchhouse C, Marquez-Luna C, Garcia-Ortiz H, Gomez-Vazquez MJ, Burtt NP, AguilarSalinas CA, et al. Sequence variants in SLC16A11 are a common risk factor for type 2 diabetes in Mexico. Nature. 2014;506(7486):97-101.

8. Pirie FJ, Motala AA, Pegorara RJ, Paruk IM, Govender T, Rom L. Variants in PPARG, KCNJ11, TCF7L2, FTO, and HHEX genes in South African subjects of Zulu descent with type 2 diabetes. Afr J Diabetes Med. 2010:18:12-6.

9. Horikawa Y, Miyake K, Yasuda K, Enya M, Hirota Y, Yamagata K, Hinokio Y, Oka Y, Iwasaki N, Iwamoto Y, et al. Replication of genome-wide association studies of type 2 diabetes susceptibility in Japan. J Clin Endocrinol Metab. 2008:93(8):3136-41.

10. Zeggini E, Scott $\sqcup$, Saxena R, Voight BF, Marchini JL, Hu T, de Bakker PI, Abecasis GR, Almgren $P$, Andersen G, et al. Meta-analysis of genome-wide association data and large-scale replication identifies additional susceptibility loci for type 2 diabetes. Nat Genet. 2008;40(5):638-45.

11. Zeggini E, Weedon MN, Lindgren CM, Frayling TM, Elliott KS, Lango H, Timpson NJ, Perry JR, Rayner NW, Freathy RM, et al. Replication of genomewide association signals in UK samples reveals risk loci for type 2 diabetes. Science. 2007;316(5829):1336-41.
12. Tong Y, Lin Y, Zhang Y, Yang J, Liu H, Zhang B. Association between TCF7L2 gene polymorphisms and susceptibility to type 2 diabetes mellitus: a large Human Genome Epidemiology (HuGE) review and meta-analysis. BMC Med Genet. 2009:10:15.

13. Wu Y, Li H, Loos RJ, Yu Z, Ye X, Chen L, Pan A, Hu FB, Lin X. Common variants in CDKAL1, CDKN2A/B, IGF2BP2, SLC30A8, and HHEX/IDE genes are associated with type 2 diabetes and impaired fasting glucose in a Chinese Han population. Diabetes. 2008;57(10):2834-42.

14. Cauchi S, El Achhab Y, Choquet H, Dina C, Krempler F, Weitgasser R, Nejjari C, Patsch W, Chikri M, Meyre D, et al. TCF7L2 is reproducibly associated with type 2 diabetes in various ethnic groups: a global meta-analysis. J Mol Med (Berl). 2007:85(7):777-82.

15. Lewis JP, Palmer ND, Hicks PJ, Sale MM, Langefeld CD, Freedman Bl, Divers J, Bowden DW. Association analysis in african americans of Europeanderived type 2 diabetes single nucleotide polymorphisms from wholegenome association studies. Diabetes. 2008:57(8):2220-5.

16. Ezzidi I, Mtiraoui N, Cauchi S, Vaillant E, Dechaume A, Chaieb M, Kacem M, Almawi WY, Froguel P, Mahjoub T, et al. Contribution of type 2 diabetes associated loci in the Arabic population from Tunisia: a case-control study. BMC Med Genet. 2009;10:33.

17. Guewo-Fokeng M, Sobngwi E, Atogho-Tiedeu B, Donfack OS, Noubiap JJ, Ngwa EN, Mato-Mofo EP, Fosso PP, Djahmeni E, Djokam-Dadjeu R, et al. Contribution of the TCF7L2 rs7903146 (C/T) gene polymorphism to the susceptibility to type 2 diabetes mellitus in Cameroon. J Diabetes Metab Disord. 2015;14:26

18. Alsmadi O, Al-Rubeaan K, Wakil SM, Imtiaz F, Mohamed G, Al-Saud H, AlSaud NA, Aldaghri N, Mohammad S, Meyer BF. Genetic study of Saudi diabetes (GSSD): significant association of the KCNJ11 E23K polymorphism with type 2 diabetes. Diabetes Metab Res Rev. 2008;24(2):137-40.

19. Ereqat S, Nasereddin A, Cauchi S, Azmi K, Abdeen Z, Amin R. Association of a common variant in TCF7L2 gene with type 2 diabetes mellitus in the Palestinian population. Acta Diabetol. 2010;47 Suppl 1:195-8.

20. Mahajan A, Go MJ, Zhang W, Below JE, Gaulton KJ, Ferreira T, Horikoshi M, Johnson AD, Ng MC, Prokopenko I, et al. Genome-wide trans-ancestry meta-analysis provides insight into the genetic architecture of type 2 diabetes susceptibility. Nat Genet. 2014;46(3):234-44.

21. Alsmadi O, Al-Rubeaan K, Mohamed G, Alkayal F, Al-Saud H, Al-Saud NA, AlDaghri N, Mohammad S, Meyer BF. Weak or no association of TCF7L2 variants with Type 2 diabetes risk in an Arab population. BMC Med Genet. 2008;9:72.

22. Al Safar HS, Cordell HJ, Jafer O, Anderson D, Jamieson SE, Fakiola M, Khazanehdari K, Tay GK, Blackwell JM. A genome-wide search for type 2 diabetes susceptibility genes in an extended Arab family. AnnHumGenet. 2013:77(6):488-503.

23. Al-Sinani S, Woodhouse N, Al-Mamari A, Al-Shafie O, Al-Shafaee M, AlYahyaee S, Hassan M, Jaju D, Al-Hashmi K, Al-Abri M, et al. Association of gene variants with susceptibility to type 2 diabetes among Omanis. World J Diabetes. 2015:6(2):358-66.

24. Alberti $\mathrm{KG}$, Zimmet PZ. Definition, diagnosis and classification of diabetes mellitus and its complications. Part 1: diagnosis and classification of diabetes mellitus provisional report of a WHO consultation. Diabet Med. 1998;15(7):539-53.

25. Saadi H, Nagelkerke N, Carruthers SG, Benedict S, Abdulkhalek S, Reed R, Lukic M, Nicholls MG. Association of TCF7L2 polymorphism with diabetes mellitus, metabolic syndrome, and markers of beta cell function and insulin resistance in a population-based sample of Emirati subjects. Diabetes Res Clin Pract. 2008:80(3):392-8.

26. Jensen DP, Urhammer SA, Eiberg H, Borch-Johnsen K, Jorgensen T, Hansen $\mathrm{T}$, Pedersen $\mathrm{O}$. Variation in CAPN10 in relation to type 2 diabetes, obesity and quantitative metabolic traits: studies in 6018 whites. Mol Genet Metab. 2006;89(4):360-7.

27. Ezzidi I, Turki A, Messaoudi S, Chaieb M, Kacem M, Al-Khateeb GM, Mahjoub T, Almawi WY, Mtiraoui N. Common polymorphisms of calpain-10 and the risk of Type 2 Diabetes in a Tunisian Arab population: a case-control study. BMC Med Genet. 2010;11:75.

28. Kilpelainen TO, Lakka TA, Laaksonen DE, Lindstrom J, Eriksson JG, Valle TT, Hamalainen H, llanne-Parikka P, Keinanen-Kiukaanniemi S, Lindi V, et al. SNPs in PPARG associate with type 2 diabetes and interact with physical activity. Med Sci Sports Exerc. 2008;40(1):25-33.

29. Phani NM, Guddattu V, Bellampalli R, Seenappa V, Adhikari P, Nagri SK, SC DS, Mundyat GP, Satyamoorthy K, Rai PS. Population specific impact of genetic variants in KCNJ11 gene to type 2 diabetes: a case-control and meta-analysis study. PLoS ONE. 2014;9(9), e107021. 
30. Purcell S, Neale B, Todd-Brown K, Thomas L, Ferreira MA, Bender D, Maller J, Sklar P, de Bakker PI, Daly MJ, et al. PLINK: a tool set for whole-genome association and population-based linkage analyses. Am J Hum Genet. 2007;81(3):559-75.

31. Hindorff LA, Junkins HA, Mehta JP, Manolio TA. A Catalog of Published Genome-Wide Association Studies. Available at: www.genome.gov/ 26525384. Accessed [22 September 2015]. 2009.

32. Hanis CL, Boerwinkle E, Chakraborty R, Ellsworth DL, Concannon P, Stirling B, Morrison VA, Wapelhorst B, Spielman RS, Gogolin-Ewens KJ, et al. A genome-wide search for human non-insulin-dependent (type 2) diabetes genes reveals a major susceptibility locus on chromosome 2. Nat Genet. 1996;13(2):161-6.

33. Horikawa Y, Oda N, Cox NJ, Li X, Orho-Melander M, Hara M, Hinokio Y, Lindner TH, Mashima H, Schwarz PE, et al. Genetic variation in the gene encoding calpain-10 is associated with type 2 diabetes mellitus. Nat Genet. 2000;26(2):163-75.

34. Steneberg P, Bernardo L, Edfalk S, Lundberg L, Backlund F, Ostenson CG, Edlund $\mathrm{H}$. The type 2 diabetes-associated gene ide is required for insulin secretion and suppression of alpha-synuclein levels in beta-cells. Diabetes. 2013;62(6):2004-14.

35. Chandak GR, Janipalli CS, Bhaskar S, Kulkarni SR, Mohankrishna P, Hattersley AT, Frayling TM, Yajnik CS. Common variants in the TCF7L2 gene are strongly associated with type 2 diabetes mellitus in the Indian population. Diabetologia. 2007;50(1):63-7.

36. Nanfa D, Sobngwi E, Atogho-Tiedeu B, Noubiap JJ, Donfack OS, Mofo EP, Guewo-Fokeng M, Nguimmo Metsadjio A, Ndonwi Ngwa E, Pokam Fosso P, et al. Association between the TCF7L2 rs12255372 (G/T) gene polymorphism and type 2 diabetes mellitus in a Cameroonian population: a pilot study. Clin Transl Med. 2015:4:17.

37. Acharya S, Al-Elq A, Al-Nafaie A, Muzaheed M, Al-Ali A. Type 2 diabetes mellitus susceptibility gene TCF7L2 is strongly associated with hyperglycemia in the Saudi Arabia Population of the eastern province of Saudi Arabia. Eur Rev Med Pharmacol Sci. 2015;19(16):3100-6.

38. Al-Safar H, Hassoun A, Almazrouei S, Kamal W, Afandi B, Rais N. Association of the Genetic Polymorphisms in Transcription Factor 7-Like 2 and Peroxisome Proliferator-Activated Receptors- gamma 2 with Type 2 Diabetes Mellitus and Its Interaction with Obesity Status in Emirati Population. J Diabetes Res. 2015:2015:129695.

39. Rafati R, Jalal R, Asoodeh A, Matin MM. Association of rs12255372 (TCF7L2) and D76N (PDX-1) Polymorphisms with Type 2 Diabetes in a Population Living in Northeast Iran. Arch Iran Med. 2015;18(6):376-8.

40. Zeggini E, McCarthy MI. TCF7L2: the biggest story in diabetes genetics since HLA? Diabetologia. 2007;50(1):1-4.

41. Guo T, Hanson RL, Traurig M, Muller YL, Ma L, Mack J, Kobes S, Knowler WC, Bogardus C, Baier $\sqcup$. TCF7L2 is not a major susceptibility gene for type 2 diabetes in Pima Indians: analysis of 3,501 individuals. Diabetes. 2007;56(12):3082-8.

42. Anderson D, Cordell HJ, Fakiola M, Francis RW, Syn G, Scaman ES, Davis E, Miles SJ, McLeay T, Jamieson SE, et al. First genome-wide association study in an Australian aboriginal population provides insights into genetic risk factors for body mass index and type 2 diabetes. PLoS ONE. 2015;10(3), e0119333.

43. Migliorini $\mathrm{A}$, Lickert $\mathrm{H}$. Beyond association: A functional role for Tcf7l2 in beta-cell development. Mol metab. 2015;4(5):365-6.

44. Lyssenko V, Lupi R, Marchetti P, Del Guerra S, Orho-Melander M, Almgren P, Sjogren M, Ling C, Eriksson KF, Lethagen AL, et al. Mechanisms by which common variants in the TCF7L2 gene increase risk of type 2 diabetes. J Clin Invest. 2007;117(8):2155-63.

\section{Submit your next manuscript to BioMed Central and we will help you at every step:}

- We accept pre-submission inquiries

- Our selector tool helps you to find the most relevant journal

- We provide round the clock customer support

- Convenient online submission

- Thorough peer review

- Inclusion in PubMed and all major indexing services

- Maximum visibility for your research

Submit your manuscript at www.biomedcentral.com/submit
C Biomed Central 